How and why were these effects kept off the table? This seems to be a missed opportunity to tell a potentially powerful story about the socio-political construction of scientific assessments.

Like all good writing, these books leave the reader wishing for more: For example, I would have liked the authors to pick apart and compare the story of ozone diplomacy with that of other complex, science-based environmental-management issues, such as the various UNEP regional seas agreements, the Bonn Convention for the protection of the Rhine, or the Convention on International Trade in Endangered Species of Wild Fauna and Flora. Although not global in scope, these and other environmental regimes are also hypercomplex amalgams of scientific information, assessment process and political deliberation. Did ozone diplomacy follow well-established models of behaviour, break completely with past exercises in regime formation, or do a little of both?

Both versions of Protecting the Ozone Layer demonstrate that the path between scientific findings and policy formulation is anything but transparent, direct or linear. Instead, the relationship is mediated through a complex web of social, institutional and individual factors, acquiring context and meaning as they are embedded in larger narratives. Charles Herrick is at Stratus Consulting Inc., 1920 L Street, Washington, DC 20036, USA.

\section{Getting up to speed}

Principles of Animal Locomotion by R. McNeill Alexander

Princeton University Press: 2003. 376 pp.

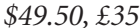

\section{Stephen Gatesy}

How did the chicken cross the road? A neurobiologist might answer that commands from the central nervous system, modulated by sensory feedback, generated cyclical walking movements. Alternatively, a physiologist could say that walking came about through myosin's interaction with actin, which created muscular tension to produce the necessary joint torques. On the other hand, a biomechanist might view the whole bird as a point mass rising and falling with each step, transforming gravitational potential energy into forward kinetic energy and back again, like an inverted pendulum. Such disparate responses highlight the wonderfully intricate and dynamic interplay that transpires when animals move through their environment.

In Principles of Animal Locomotion, $\mathrm{R}$. McNeill Alexander approaches movement from a physical point of view. He seeks to explore the mechanical principles at work in organisms as different as burrowing earthworms and hovering hummingbirds. More-

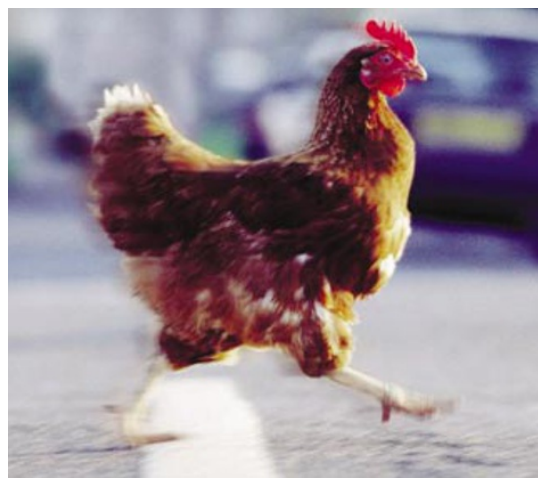

How did the chicken cross the road?

over, he tries to account for the metabolic cost, and thus the relative energetic merit, of alternative forms of locomotion. These might seem like lofty goals, but Alexander is up to the task. His publications over the past six decades span such topics as swimming, scaling, gaits, elastic storage, and optimization (to name just a few), giving him the breadth and depth needed to summarize the field.

The book begins with a lucid summary of performance objectives - speed, acceleration, manoeuvrability, endurance, economy and stability - and their potential relationship to fitness. This is followed by a brief discussion of compromises (not all of the objectives are compatible), constraints (not all changes are possible) and optimization (which solution is best?). Alexander then covers muscle mechanics, energetics, scaling and recording techniques, before delving into specific forms of locomotion. Terrestrial progression is addressed first through simple theoretical models and then by examining walking, running, hopping, climbing, jumping, crawling and burrowing in real animals. Aerial and aquatic locomotion are then tackled, although cilia-driven propulsion is not included. There is also a chapter on the effectiveness of devices for augmenting human locomotion.

Although this book is aimed at an audience ranging from advanced undergraduates to researchers and university teachers, I think that most undergraduates will be overwhelmed and intimidated if it is used as a textbook. Alexander packs in so much information that clarity is often sacrificed for coverage. His curt style is so direct and quantitative (equations are ubiquitous, starting on page 2) that every paragraph is extremely dense. But despite its failings as a textbook, it is an excellent reference tome. Citations (up to 2001) and 33 pages of references (of which 77 are authored by Alexander) will quickly direct readers to the relevant literature. I will use Principles of Animal Locomotion and recommend it to my graduate students.

Alexander's facility with simple, quantitative models is both a strength and a weakness. Regrettably, the translation from a living, breathing animal to a mathematical representation of its underlying physics is never explained. In creating such models, which details can be omitted, and which need to be retained? If Alexander wants to appeal to a broad range of scientists, he must take

\title{
Standing the test of time
}

The centenary volume of Munich's Deutsches Museum, Ingenious Inventions and Masterpieces of Science and Technology, is a celebration of the long and often troubled history of one of the world's oldest, and largest, technology museums.

The Deutsches Museum was founded in 1903 by Oskar von Miller, a pioneer of electrical engineering. Work on its permanent home - an architectural jewel on an island in the Isar river, which flows through Munich - was begun in 1906 , but its completion was delayed first by war and then by hyper-inflation. The building was finally opened in 1925 with great fanfare in a celebration that is sometimes referred to as the Weimar Republic's last party.

A few happy years followed before history struck again. The Nazis didn't like von Miller's cosmopolitan aspirations for the museum, and the Allied forces' bombs had no pity, destroying much of the building as well as around 20,000 display items. But the museum survived and remains one of the world's most significant technology museums.

This coffee-table book, edited by the museum's director, Wolf Peter Fehlhammer, includes illustrations of treasures from the past along with current exhibitions. These range from

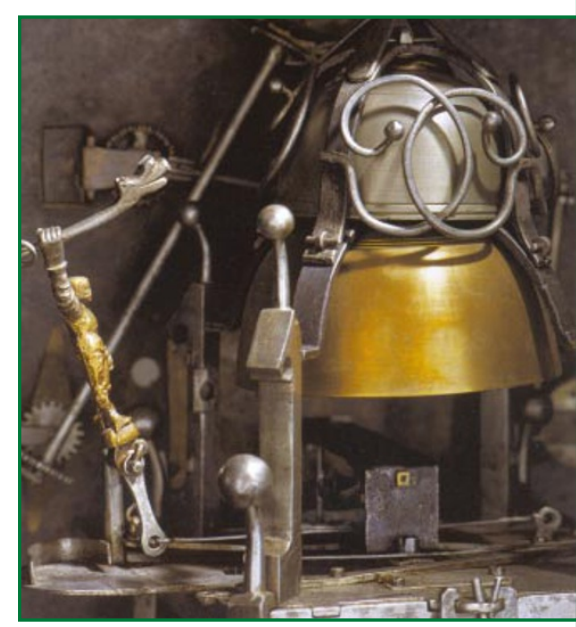

Otto von Guericke's first vacuum pump and hemispheres, forged in 1663, to the 1962 recreation of the Altamira cave with its Stone Age paintings, to the Helios space probes, solar observatories constructed in Munich and launched in the 1970s. The illustration shows a timepiece dating from 1630 from southern Germany, one of the earliest instruments for measuring time. 


\section{Nets and neuroses}

\section{The obsessional art of Yayoi Kusama uses repetition to express her fears of obliteration in infinity.}

\section{Martin Kemp}

It is increasingly common for artists to make a conscious effort to embed science into their creative procedures. We accordingly feel justified in analysing their works in relation to the relevant sciences. But what about works that evoke strong scientific resonance without any evidence that their creators were thinking about science at all? A striking case in point are the huge paintings and installations by the Japanese artist Yayoi Kusama.

This dilemma is encapsulated by the reaction of Philip Campbell, editor of Nature, when he visited the retrospective of Kusama's works at the Bass Museum of Art in Miami Beach, Florida, housed in a new gallery designed by Arata Isozaki. Campbell says that "her flat patterns, such as the infinity nets, are fascinating and seem to have an elusive natural character, as opposed to an artificial character". He adds: "It's hard to judge the power of these sometimes gigantic canvases." But Campbell suggests some themes that spring to mind, such as pattern analysis, and says they are reminiscent of crystallographic and biological patterns. Yet there is no sign in any of Kusama's many pronouncements of her conscious engagement with such things.

The 'infinity nets' are composed of cellular structures of potentially unlimited extension. Each cell is similar, leading to endless repetition, yet is unique. At one level the nets are "mechanical" and "empty", as Kusama says, yet they are no more empty and undifferentiated than cosmic space, plastic foam or cross-sections of cork.

One of the more recent variations on the theme is Infinity Stars from 1995, which stretches to 17 feet in length. This work exemplifies how the repeated shapes - in this case a myriad of round 'lights' punctuating a cellular membrane - have organized themselves around certain intuitive principles of distribution, packing and symmetry. The very act of repeatedly stringing out the reticulate structure sets parameters on its possible morphology, much like the physico-chemical constraints imposed on cells in tissues or the space-time dimensions of cosmic branes.

But it would be wrong to write about the infinity

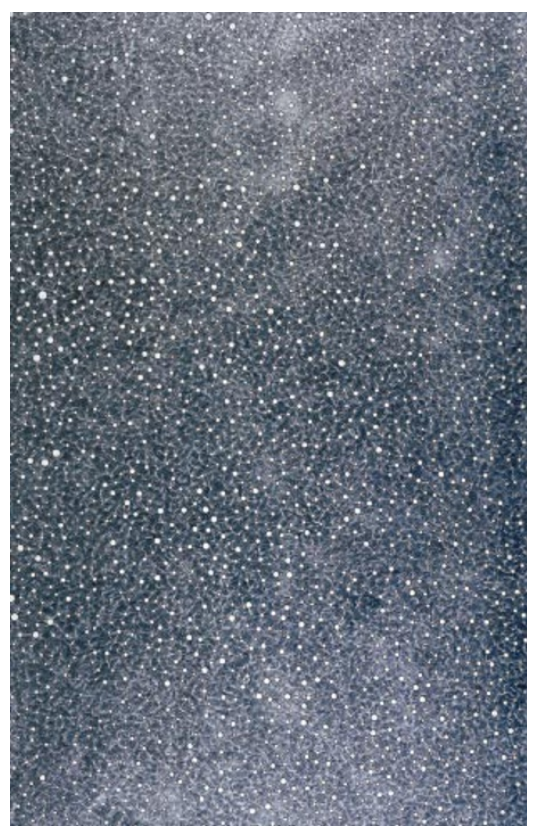

Spot the difference: this detail from Infinity Stars shows how Yayoi Kusama uses repetition.

nets as if they are only formal exercises that exhibit an unconscious rapprochement with certain classes of scientific image. They arise instead from deep psychic motivations, and are saturated with Kusama's fears, obsessions and hallucinations. She has, since childhood, suffered from obsessive neurosis, and for the past 20 years has voluntarily resided in a mental hospital in Japan. She has been obsessed by the hypnotic effects of endless repetition and accumulation, and both proclaims and fears the obliteration of the individual in scaleless infinity and limitless time. She exploits repetition in a manner akin to chanting in religious rituals or to the mesmerizing quality of an endlessly repeated phrase that loses all focused content.

Kusama has been one of the most remarkable and fertile artists of the second half of the twentieth century. She arrived in New York as a 29-year-old in 1958 and contributed energetically to the heady art world of the 1960s and 1970s. Andy Warhol's notorious Factory set the tone of social ferment and creative anarchy. Kusama herself participated uninhibitedly, staging outrageous happenings with nude performers. She also made large accumulative sculptures densely covered in phalluses, set up extravagant installations with mirrors, designed extreme fashion and wrote unsettling poetry.

There is no simple answer to our dilemma of whether Kusama's nets have any connection with science. At the level of conscious address, the answer is probably no. And in as much as their expressionistic role is to evoke subjective feelings of obliteration, depersonalization and hallucination, the answer is again no (or apparently so). However, if we look at how they make their effect on a viewer, by tapping into ubiquitous modes of repetitive pattern formation - the effect to which Campbell reacted - we can see that they can be powerfully resonant for scientific observers who delve into the order of things of a kind, albeit for their own, very different purposes.

Martin Kemp is in the Department of the History of Art, University of Oxford, Oxford OX12BE, UK.

Yayoi Kusama's work will be on show at the Bass Museum of Art in Miami Beach, Florida, until 11 May.

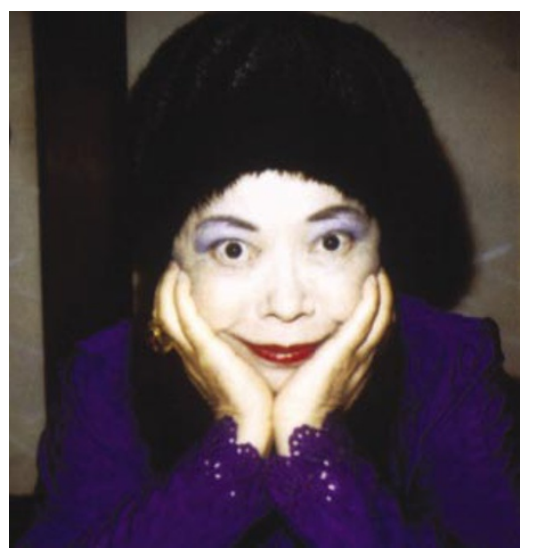

Yayoi Kusama: influential for almost 50 years. readers step-by-step through the transition to a mechanical perspective, rather than just diving in. Most biologists, even those with training in mathematics and physics, don't think like engineers.

Finally, I lament the book's lack of phylogenetic foundation. Despite the first chapter's evolutionary tone, Alexander never returns to ancestry or history; instead, each organism is treated as a separate case study of adaptation. In a disappointingly short epilogue (just five-and-a-half pages), he attempts "some generalizations about locomotion", but comes to few conclusions. His search for generalizations fails because he treats each organism as an independent point on a graph, rather than as a member of a hierarchical tree of life. From an evolutionary perspective, physical mechanisms that are shared among taxa are either homologous or convergent, not just common.

If most walking animals, whether vertebrate or arthropod, use an inverted pendulum mechanism to save energy, how many times has this evolved? How did organisms that were optimized for swimming evolve into organisms optimized for running? And then how did runners evolve into organisms that are optimized for flying? Such transitions are completely ignored in this book.

Principles of Animal Locomotion is a valuable reference book written by a leader in the field. But it also serves as proof that enough studies have accumulated to warrant an evolutionary analysis of locomotor mechanics — a synthesis that I await eagerly.

Stephen Gatesy is in the Department of Ecology and Evolutionary Biology, Brown University, Providence, Rhode Island 02912, USA. 